probabilities for alternative trajectories of future population ${ }^{6,7}$. The trajectories in such models typically contain brief episodes of rapid change and are far from smooth. Such an approach is particularly valuable in assessing social programmes (for instance the US social security system) whose future is sensitive to the timing and pattern of demographic change.

Dynamic approaches tend to be 'formal', requiring an explicit mapping from historical information into processes of change. Static scenarios tend to be 'subjective', because they rarely make explicit how history is mapped into the future. Dynamic approaches are criticized for an over-reliance on history, on the grounds that the future may hold unknown revolutionary change. That may be true, but the history of this century is surely characterized by tumult and sudden change. Besides, the static approach relies just as heavily on analysing history which is what makes experts.

The difference between static and dynamic approaches is partly a matter of timescales: fertility change between 1997 and 2050, for instance, is driven by processes that work over two or more human generations. The actual course of transition is marked by changes on a generational timescale, of the sort whose signature is writ large in the demographic history of any country. The overarching goal is the enterprise of developing probabilistic forecasts that are directly useful tools for decision and analy- sis. Withluck, demographers will point the way for ecological and environmental forecasts, which are also bedevilled by uncertainty.

Lutz et al. make a persuasive case that global population growth is slowing down, which should soothe those who see population as the primary cause of the world's ills. But they predict high odds of at least a half-century of substantial global population growth as well as a tremendous increase in the proportion of older people in every country. Those involved in economic, social and population policy still have lots to worry about. International economic policy has a large part to play in helping today's most populous countries stay on their courses of fertility decline. This is an important role if we are to steer away from the unlikely but real possibility that fertility will start to rise again. For individuals, families and countries everywhere, the largest question of the next few decades will almost surely be, how to age gracefully.

Shripad Tuljapurkar is at Mountain View Research, 2251 Grant Road, Suite A, Los Altos, California

94024, USA.

e-mail: tulja@mvr.org

1. Lutz, W. L., Sanderson, W. \& Scherbov, S. Nature 387, 803-805 (1997)

2. Lee, R. D. Int. J. Forecast. 8, 315-327 (1992)

3. Malkiel, B. G. A Random Walk Down Wall Street 3rd edn (Norton, New York, 1992)

4. Keilman, N. Uncertainty in Population Forecasting (Swets \& Zeitlinger, Amsterdam, 1990)

Alho, J. A. J. R. Statist. Soc. A 80, 306-314 (1996).

6. Lee, R. D. \& Tuljapurkar, S. J. Am. Statist. Ass. 89, 1175-1189 (1994). Alho, J. A. \& Spencer, B. J. Official Stats 7, 295-310 (1991).

\title{
Super slippery solids
}

\section{Somuri Prasad and Jeffrey Zabinski}

t would appear that primitive man had a clear understanding of the importance of friction and lubrication - transportation of massive objects by the Egyptians in 2000 BC, for example, was facilitated by using sledges dragged over lubricated wooden boards. The role of a lubricant is similar to that of a peacekeeping force: its main function is to prevent the opposing surfaces from coming into close contact with each other at the atomic level. Mostlubricants areliquids, but when the operating conditions (such as high or low temperature, or vacuum) are beyond the liquid realm, attention turns to solid materials. The most common solid lubricants are graphite and the transition-metal dichalcogenides, $\mathrm{MX}_{2}$ (where $\mathrm{M}$ is molybdenum or tungsten, and $\mathrm{X}$ is sulphur, selenium or tellurium). But both graphite and the metal dichalcogenides have certain inherent deficiencies. The synthesis of hollow nanoparticles of tungsten disulphide $\left(\mathrm{WS}_{2}\right)$ similar to fullerenes and nanotubes, reported by Tenne and co-workers on page 791 of this issue ${ }^{1}$, offers some exciting possibilities for a new generation of solid lubricants.
First, how do traditional solid lubricants work? The low friction of both graphite and metal dichalcogenides is usually due to interplanar mechanical weakness, intrinsic to their crystal structures. For example, $\mathrm{WS}_{2}$ crystallizes in the hexagonal structure, in which a sheet of tungsten atoms is sandwiched between two hexagonally packed sulphur layers (Fig. 1, overleaf). The bonding within the S-W-S sandwich is covalent, whereas the sandwiches themselves are held together by weak Van der Waals forces, resulting in interplanar mechanical weakness. Under the action of a shear force, intracrystalline slip occurs in the weak interplanar regions. This mechanism is responsible for the formation of smooth transfer films by wear: the new surfaces, created by separating the weakly bonded sandwiches, are quite inert. They can easily slide back and forth over one another (by intercrystalline slip), thereby providing lubrication.

But there is a major obstacle to lubrication by metal dichalcogenides: the presence of unsaturated or dangling bonds. In a typical layered structure $\left(2 \mathrm{H}-\mathrm{WS}_{2}\right)$, the obvious

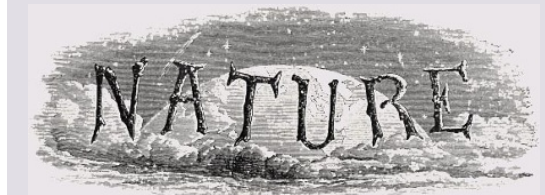

100 YEARS AGO

Another name must be added to the long list of martyrs who have given up their lives while endeavouring to effect the conquest of the air. The latest victim is Dr. Wölfert, who had devoted many years to the problem of aerial navigation, and who claimed to have invented a navigable balloon. The Berlin correspondent of the Times says that Dr. Wölfert had made an arrangement with the officers of the ballooning section of the army to put his invention to a practical test at Tempelhof on Saturday last. ... At first the balloon ascended steadily and began to make good progress... . Suddenly, however, when the balloon was sailing at a height of about $\mathbf{1 0 0 0}$ feet, flames shot up from the car and the balloon exploded with a loud report and was precipitated, a burning mass, into a wood-yard below. The mounted officers hurried to the spot, and, after the flames had with great difficulty been partially extinguished, the mutilated remains of Dr. Wölfert and his companion were found amidst the ruins of the car. It is believed that the valve of the balloon was opened with the intention of descending, and that the gas, in escaping from the balloon, became ignited by the benzene. From Nature 17 June 1897.

\section{YEARS AGO}

The Committee's programme, as outlined in communications recently received from Prof. Einstein, is to see that the following simple facts, which are accepted by all scientific workers, are given the widest possible publicity. They are: (1) that atomic bombs can now be made cheaply and in quantity, with future bombs likely to be even more powerful and destructive; (2) that there is no military defence against atomic bombs; (3) that other nations can discover for themselves the processes kept secret by the United States; (4) that preparedness against atomic warfare is futile and, if attempted, will ruin the structure of social order; (5) that if war does occur, atomic bombs will definitely be used, and will surely destroy our civilization; and (6) that international control of atomic energy and, ultimately, the elimination of war, is the only solution to the problem. - 'Emergency Committee of Atomic Scientists'

From Nature 21 June 1947. 


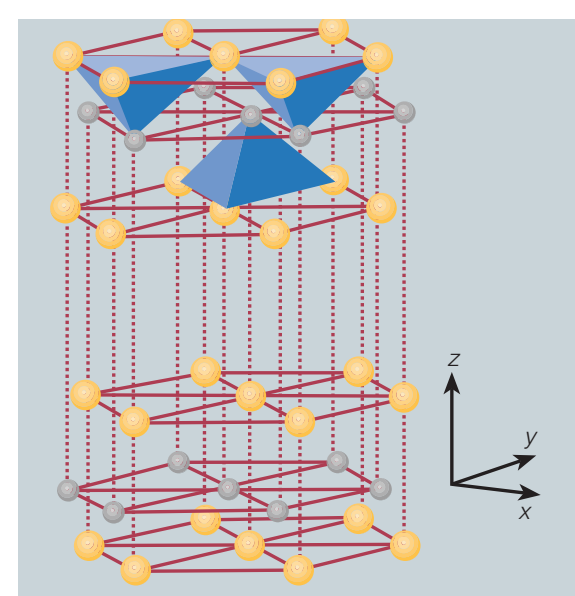

Figure 1 Crystal structure of hexagonal tungsten disulphide, $2 \mathrm{H}-\mathrm{WS}_{2}$.

source of dangling bonds is an edge plane. Furthermore, the propagation of a pre-existing crack in a $\mathrm{WS}_{2}$ film will break a few covalent bonds and create more unsaturated bonds. If sliding takes place in humid air, such activated surfaces can instantly react with moisture and oxygen in the surrounding environment, forming $\mathrm{WO}_{3}$. Thus, the tribological (friction and wear) behaviour of metal dichalcogenides is strongly dependent on their environment. For instance, when the test environment is switched from dry nitrogen to humid $\mathrm{air}^{2}$, the friction coefficient of a typical $\mathrm{WS}_{2}$ film can rise from $0.03-0.04$ to $0.15-0.20$, decreasing its wear life by several orders of magnitude. In contrast, graphite loses its lubricating property in a vacuum, as the complete absence of adsorbed vapours makes it difficult to shear the layers. According to our current understanding, no material can act as a solid lubricant in all these environments. Has such a material now been discovered?

Tenne and co-workers ${ }^{3}$ first observed closed structures of $\mathrm{WS}_{2}$, ranging in size from 10 to $100 \mathrm{~nm}$, when they annealed tungsten films at $1,000{ }^{\circ} \mathrm{C}$ in a reducing $\mathrm{H}_{2} \mathrm{~S}$ atmosphere (see Fig. 2). The distance between two fringes in their lattice images is $0.615 \mathrm{~nm}$, the same as the distance between two neighbouring sandwiches in an open $2 \mathrm{H}-\mathrm{WS}_{2}$ structure. Tenne and co-workers ${ }^{3}$

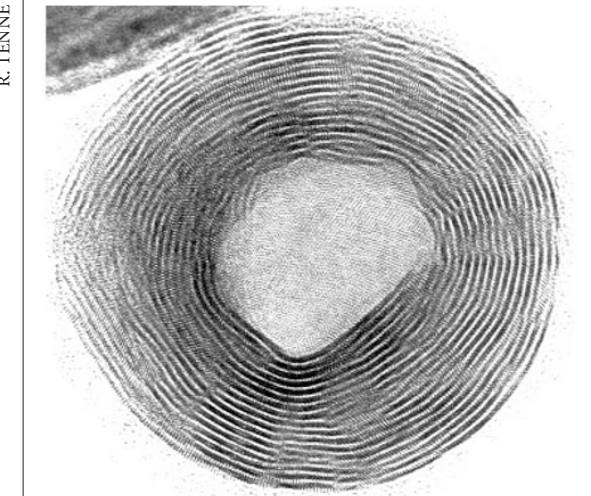

Figure 2 High-resolution electron micrograph of a WS $S_{2}$ nanoparticle. argue that the curling and closure of $\mathrm{WS}_{2}$ networks was probably induced by thermal stresses $\left(1,000{ }^{\circ} \mathrm{C}\right.$ is a fairly high temperature) and facilitated by structural defects such as edge dislocations, or by contaminant atoms, such as oxygen, that came from the quartz substrate. The authors have also made nanoparticles of $\mathrm{WS}_{2}\left(\mathrm{HN}-\mathrm{WS}_{2}\right)$ in gram quantities by a sol-gel reaction ${ }^{1}$.

The dangling bonds that are responsible for causing oxidation in layered $2 \mathrm{H}-\mathrm{WS}_{2}$ structures are no longer present in $\mathrm{HN}-\mathrm{WS}_{2}$ particles. Does this mean that we now have a super solid that can effectively lubricate in all environments? The intracrystalline slip that is responsible for creating smooth transfer films is no longer present in this powder, as appreciable shear between inner and outer closed layers is almost impossible. By the same token, $\mathrm{HN}-\mathrm{WS}_{2}$ powder cannot be burnished like the traditional layered structures. Indeed, Tenne and colleagues ${ }^{1}$ had to roughen the substrate and use a drop of mineral oil to avoid runaway of the nanopowder during friction measurements. Yet the friction coefficient and wear rate for nano $\mathrm{WS}_{2}$ powder measured in oil were superior to those of traditional $\mathrm{WS}_{2}$ and $\mathrm{MoS}_{2}$ powders ${ }^{1}$. This suggests that a different mechanism is controlling the tribological behaviour of nanoparticles.

The mechanism oflubrication in the case of hollow nanopowder appears to be one of rolling and not sliding. By virtue of their extremely small size, the $\mathrm{HN}$ particles can fill the submicrometre-sized valleys between asperities and prevent asperity contact between mating surfaces. This, coupled with their rounded shape, opens the possibility that they undergo rolling friction at the nanometre level. Furthermore, elimination of dangling bonds makes the HN particles chemically inert, so the particles are less likely to stick to the substrate, or to one another. Their hollow-cage structure imparts high elasticity, and elastic deformations (as opposed to inelastic deformations) diminish the energy dissipation associated with friction. These are some of the characteristics that make the hollow nanoparticles of metal dichalcogenides potential candidates for miniature rollingelement bearings.

Perhaps, in the coming decades, we might see a micrometre-sized rolling-element bearing using hollow nanotubes of metal dichalcogenide. But even in the near future, these small, round, inert nanoparticles should find some applications in powder lubrication, and as additives in lubricating oils.

Somuri Prasad and Jeffrey Zabinski are in the

Materials Directorate of the Wright Laboratory,

Wright Patterson Air Force Base, Ohio 45433-7750,

USA.

1. Rapoport, L. et al. Nature 387, 791-793 (1997).

2. Prasad, S. V. \& Zabinski, J. S. J. Mater. Sci. Lett. 11, 1413-1415 (1993).

3. Tenne, R. et al. Nature 360, 444-446 (1992).

\section{Daedalus \\ A science futures market}

When a manager starts to depend on performance indicators, he is losing his grip. He should know what his concern is up to, without juggling arcane ratios. And once performance indicators are taken seriously, doom is certain. The organization switches its goals from whatever it should be doing, to maximizing the indicators.

On this criterion, scientific research is in a bad way. Performance indicators abound - impact factors, citation counts, publications per head or per grant dollar, and so on. Mutual backscratching cliques cite each other furiously in all their papers; journals parasitized by such publications proudly proclaim their impact factors; grant money flows to individuals and organizations who can show the best performance indicators. Hence the delight and outrage over the recent researchassessment ranking of UK universities.

Daedalus now has a better way. Science is no longer a collective endeavour to understand the physical world; it is a competitive struggle to acquire grant money. The time has come to put it on a sound capitalistic basis. So Daedalus proposes a scientific stock exchange. University departments, and even individual scientists, could issue shares in their research programmes, and shareholders would receive a proportion of each grant subsequently won by the issuer.

At once the 'invisible hand' of the market would work its benevolent magic. Researchers would issue prospectuses arguing the strength of their teams, the brilliance of their hypotheses and the convincing nature of their pilot experiments. The grant-worthiness of such claims would be judged by shrewd and critical scientific investors. The intellectual debate would be sharpened by the attempts of competing shareholders to talk up the projects they had backed, or to criticize ones in which they had taken a 'stag' position. In the same way, the scientific grapevine would instantly evaluate alleged breakthroughs or setbacks, and signal its opinion through the relevant share prices.

Research would be transformed. Any scientist could obtain prompt 'seed-corn money' for his ideas by issuing shares. Progress on all research fronts could be assessed daily in the financial papers. And a whole new scientific career would open up. Elderly researchers would no longer see administration yawning inescapably in front of them. Their experience and insight would gain them steady money punting on the scientific market.

David Jones 